\title{
Nuclear debate goes critical in Japan
}

\section{Robert Triendll}

\section{The apparent incompetence of Japanese authorities in dealing with last week's fire at a nuclear plant is taking its toll of public confidence.}

T he Japanese government and the semi-public Power Reactor and Nuclear Fuel Development Corporation (PNC) have come in for severe criticism for their handling of an accident last week at a nuclear fuel recycling plant at Tokai village in Ibaraki Prefecture northeast of Tokyo.

The fire broke out on the morning of 11 March in a facility used for the 'bitumenization' of low-level radioactive waste. It was followed ten hours later by an explosion that blew out doors and windows.

Sloppiness in extinguishing the fire and in the subsequent clean-up appear to have resulted in volatile asphalt gases filling the room, eventually causing the explosion. Contrary to PNC's initial assertion that no radiation had escaped, low doses of radioactivity were released to the environment, and at least 37 PNC workers were exposed.

Japan's prime minister, Ryutaro Hashimoto, and the president of PNC apologized publicly for the slow response to the accident. But, reflecting growing public distrust in the government's nuclear policy, the governor of Ibaraki Prefecture visited both Hashimoto and the head of the Science and Technology Agency (STA) the following day, and urged a thorough investigation of the accident as well as of safety measures at all nuclear facilities in his prefecture.

"Contrary to all that has been said over the last year on the public release of information and crisis management, this accident shows very clearly that nothing has changed," says Minako Ogisa, a spokeswoman for the Fukui Prefecture Citizens' Forum Against Nuclear Power, the largest anti-nuclear group in the prefecture where Japan's experimental fast-breeder reactor Monju is located.

\section{Long-term implications}

A senior official at STA, the agency that oversees PNC, admits that, "to restore public confidence, a sound investigation, carried out publicly, is absolutely essential".

Most analysts agree that last week's accident had "at worst the character of a major accident at a chemical processing plant", and have been surprised by the harsh public reaction. But the long-term implications for the future of Japan's nuclear fuel-cycle policy could be substantial. "While the Monju accident [in December 1995] concerned the first stage of the fuel cycle, the accident at Tokai village concerns the final stage," Ogisa points out.

Meanwhile, STA's final report on the liquid sodium leak at the Monju experimental fast-breeder reactor (see Nature 379, 196; 1996), released last month, has met considerable criticism from citizens' groups. "The ultimate reason for the accident remains untreated in the report," says Keiji Kobayashi, a professor of nuclear engineering at Kyoto University and a well known critic of Japan's fast-breeder programme.

"They do not deal with important deficiencies in PNC's approach to design and quality control," says Kobayashi. A critical assessment of the report by an expert group associated with the Fukui Prefecture citizens' forum is to be made public by the end of this month, says Kobayashi.

Earlier this year, a Fast-Breeder Reactor (FBR) Advisory Committee was set up by the Atomic Energy Commission and STA, at the request of the governors of Fukui, Niigata and Fukushima, the three prefectures where most Japanese nuclear power plants are located.

Opponents of the fast-breeder programme, and of nuclear energy in general, are relatively well represented on the committee and the agency is said to have consulted Jinzaburo Takagi, a prominent critic of Japanese nuclear policy, about the selection of committee members.

According to official sources, the FBR Advisory Committee aims at a broad reassessment of Japanese nuclear policy. An official at the agency points out that the committee is an "adventure", the outcome of which is "uncertain". He adds: "It's an entirely new situation we have no experience with. It will be necessary to proceed in an adhoc fashion, without invoking grand strategies."

But some observers dismiss this as mere tactical manoeuvring. "It's all about window dressing. What they want is to disperse criticism and pave the way for reopening Monju," says Kobayashi.

Others admit that critics have now at least found their place inside the government. "It is true that critical observers are now participating in various expert advisory bodies related to nuclear issues," says Hitoshi Yoshioka, a professor of sociology at the University of Kyushu and the leader of the antinuclear faction on the FBR Advisory Com-

\section{IMAGE UNAVAILABLE FOR COPYRIGHT REASONS}

The morning after: glass litters the recycling plant after explosion blew out windows.

mittee. But he adds that the actual role of the committee remains rather vague.

Some analysts argue that the setting up of the FBR Advisory Committee may be a sign of desperation, and even crisis, at STA. In a mood of doom about STA's nuclear fuelcycle programme, an old rivalry between the agency and the Ministry of International Trade and Industry over the control of Japanese nuclear politics could regain momentum. Takagi says: "We have been struggling with STA bureaucrats for years. Now that we have started to get along with them, we recognize that our most important opponent is elsewhere."

\section{Death knell for Monju}

After last week's accident, critics of Japan's fast-breeder programme are increasingly confident that Monju will never go on line. "Monju is a dead end," says Ogisa. Yoshioka adds: "This is something Japan is good at. Everything comes ten years too late. The start of the Japanese nuclear energy programme was ten years late. Japan's FBR programme took off with a ten-year delay, and now it will be abandoned ten years too late."

Although it may be too early to speculate about the ramifications of last week's accident for Japanese nuclear policy, there appears to be a widespread consensus that the accident may contribute to a considerable slowdown of plans to burn mixed plutonium-uranium fuel (MOX) in ordinary light-water reactors.

This plan, known as the 'pluthermal' programme, was approved by the Japanese government in early February. But reactors still have to be relicensed by local authorities to burn MOX (see Nature 385, 757; 1997). And after last week's accident they are not likely to give their approval soon.

The author is an expert on Japanese science policy currently based in Paris. 